\title{
EFEITO DE HERBICIDAS DE PRÉ-EMERGÊNCIA SOBRE O DESENVOLVIMENTO INICIAL DE ESPÉCIES ARBÓREAS
}

\author{
Robério Anastácio Ferreira ${ }^{1}$; Antonio Claudio Davide ${ }^{2}$; Elifas Nunes de Alcântara ${ }^{3}$ e \\ Marcelo Souza Motta ${ }^{4}$ \\ ${ }^{1}$ Eng. Florestal Dr. - Prof. Departamento de Engenharia Agronômica - DEA/UFS. Cidade Universitária Prof. José \\ Aloísio - Av. Marechal Rondon, S/N - Jardim Rosa Elze - 49100-000 - São Cristóvão -SE. e-mail: raf@ ufs.br; \\ ${ }^{2}$ Prof. Dr. Departamento de Ciências Florestais - DCF/UFLA. CP 37, CEP 37200-000 - Lavras, MG. e-mail: \\ acdavide@ufla.br; \\ ${ }^{3}$ Pesquisador Ph.D. EPAMIG/CTSM - EcoCentro, Lavras - MG CEP 372000. e-mail: elifas @epamig.ufla.br; \\ ${ }^{4}$ Engenheiro Florestal - Mestrando - Departamento de Ciências Florestais - DCF/UFLA. CP 37, CEP $37200-000$ - \\ Lavras, MG.
}

\section{RESUMO}

O objetivo deste trabalho foi avaliar o efeito de diferentes tratamentos com herbicidas de pré-emergência, na emergência de plântulas e desenvolvimento inicial das mudas de espécies arbóreas de matas ciliares. O experimento foi realizado em casa de vegetação, em delineamento em blocos casualizados, com cinco tratamentos e quatro repetições. Os herbicidas utilizados foram imazapyr, atrazina, acetochlor e oxyfluorfen, nas seguintes dosagens: 3,0L p.c./ha, 5,0L p.c./ha, 3,0L p.c./ha e 4,5L p.c./ha, respectivamente. Para comparação destes, foi utilizado um tratamento testemunha (sem herbicida). O acetochlor apresentou resultados satisfatórios na emergência de plântulas e na sobrevivência de mudas de Senna multijuga, Senna macranthera, Solanum granulosoleprosum e Trema micrantha. Com exceção da $T$. micrantha, as demais espécies mostraram-se altamente susceptíveis a ação do imazapyr na sobrevivência de mudas. A atrazina e o oxyfluorfen mostraram-se passíveis de utilização, mas necessita uma criteriosa avaliação quanto a definição das espécies. Deve-se enfatizar que nenhum dos herbicidas apresentou resultado igual ao tratamento controle (testemunha), quer seja na emergência de plântulas ou na sobrevivência de mudas. Os efeitos fitotóxicos observados corroboraram as informações já registradas para os herbicidas empregados. Pôde-se também constatar eficiência dos herbicidas no controle de plantas daninhas, presentes no tratamento controle (testemunha).

Palavras-chave: herbicida, pré-emergência, espécies arbóreas.

\section{EFFECT OF PRE-EMERGENCE HERBICIDES ON THE INITIAL DEVELOPMENT OF TREE SPECEIS ABSTRACT}

The objective of this work was to evaluate the effect of different treatments with pre-emergent herbicides on the emergence, survival and initial growth of seedlings of tree species from riparian forests. The experiment was conducted in a greenhouse in a randomized blocks design with four replicates and five treatments. The herbicides used were imazapyr, atrazine, acetochlor and oxyfluorfen at the rates of 3,0L p.c./ha, 5,0L p.c./ha, 3,0L p.c./ha e 4,5L p.c./ha, respectively, plus a control treatment (no herbicide). Acetochlor showed satisfactory results in the emergence and seedlings surviving of Senna multijuga, Senna macranthera, Solanum granuloso-leprosum and Trema micrantha. Imazapyr affected all other species but not $T$. micrantha in the seedlings surviving. Atrazine and oxyfluorfen can be used in some cases but it is necessary a close evaluation of each species. Herbicides did not show better results on the emergence or seedlings survival when compared to the control (no herbicide). Observed phytotoxic effects were 
similar to those described in the literature. The tested herbicides were efficient to control all weeds found in the control treatment.

Key-words: herbicides, pre-emergent, tree species.

\section{INTRODUÇÃO}

Em áreas de reflorestamento, a presença das plantas daninhas torna-se indesejável, tanto do ponto de vista silvicultural quanto econômico, uma vez que estas competem por luz, água e nutrientes. Deste modo, é necessário se fazer um monitoramento periódico para reduzir a sua infestação, fator que aumenta consideravelmente o custo da implantação. Por outro lado, do ponto de vista ecológico, a sua presença em algumas áreas, pode ser desejável por promover maior cobertura do solo, reduzindo a erosão, melhorando a estrutura física e incorporando matéria orgânica (Davide \& Botelho, 1999 e Davide et al., 2000).

No Brasil, as primeiras preocupações com o controle de plantas daninhas, em áreas de reflorestamento, surgiram na década de 80 (Rodrigues et al., 1988; Pascoal \& Nakano, 1988; Thomaz et al., 1988; Barrichelo \& Managó, 1988; Wiecheteck, 1988 e Ribeiro, 1988).

O período em que as plantas daninhas competem com as espécies cultivadas, numa determinada área, é de grande importância para se definir o sistema de manejo mais eficiente, pois quanto maior for o tempo de convivência das plantas daninhas com as espécies cultivadas, maior será a interferência da comunidade infestante (Gelmini, 1988). De acordo com DiTomaso (2000), as perdas anuais causadas pela ocorrência de plantas daninhas em vários habitats agrícolas e de reflorestamentos, nos Estados Unidos, são da ordem de 2 milhões de dólares.

Dentre os métodos que podem ser empregados para o controle de plantas daninhas, o controle químico, por apresentar resultados de forma rápida, vem sendo empregado em maior escala. No entanto, alguns critérios devem ser observados quando da sua utilização, tais como a escolha do produto a ser usado, a necessidade de mão-de-obra especializada para realizar a operação de aplicação e, ainda, os risco de contaminação do ambiente (Gelmini, 1988).

Os trabalhos realizados na década de 80, com aplicação de oxyfluorfen e glyphosate, em áreas de reflorestamento, tinham como objetivo reduzir a competição das plantas daninhas na fase inicial de implantação e, consequentemente, acelerar o estabelecimento das mudas. Os resultados obtidos foram satisfatórios com estes herbicidas, tornando-se mais um fator a ser considerado, com o intuito de aumentar o rendimento dos povoamentos e reduzir o custo de implantação. No entanto, o mau uso de herbicidas, em algumas situações, pode promover efeitos indesejáveis e irreversíveis no ecossistema (Pitelli \& Karam, 1988), pois de acordo com Rodrigues \& Almeida (1998), eles podem causar intoxicações em aves, peixes e abelhas.

Outro fator que deve ser considerado, é o pouco conhecimento sobre o comportamento das espécies florestais sob ação de herbicidas, no que diz respeito à seletividade, à resistência e aos efeitos fitotóxicos.

$\mathrm{Na}$ implantação de florestas ou recuperação de áreas degradadas, deve-se enfatizar que, as Leis federal e estadual proíbem que este método seja empregado em áreas de preservação permanente (Lei.., 1991). Por outro lado, em algumas situações e sob rigoroso controle técnico, esta pode ser uma alternativa a ser considerada, na tentativa de assegurar a revegetação nestas áreas.

Pelo exposto, este trabalho teve como objetivo: avaliar o efeito de diferentes tratamentos com herbicidas de pré-emergência, na emergência de plântulas, na sobrevivência e no desenvolvimento inicial de mudas de espécies arbóreas de ocorrência em matas ciliares. 


\section{MATERIAL E MÉTODOS}

Para a realização do trabalho foram empregadas quatro espécies arbóreas de ocorrência em matas ciliares: Senna multijuga (Rich.) Irwin et Barn.; Senna macranthera (Collad.) Irwin et Barn.; Solanum granuloso-leprosum Dunal e Trema micrantha (L.) Blume).

Os frutos das espécies selecionadas foram colhidos na região de Lavras - MG. A cidade de Lavras localiza-se a $21^{\circ} 14^{\prime} \mathrm{S}$ e $45^{\circ} 0$ ' W, a $900 \mathrm{~m}$ de altitude. Apresenta clima do tipo $\mathrm{Cwb}$ (Clima temperado úmido com inverno seco), segundo a classificação de Köppen. A temperatura média anual é de $19,4{ }^{\circ} \mathrm{C}$ e a precipitação média anual é de $1529.7 \mathrm{~mm}$ (Brasil, 1992).

O experimento foi realizado em casa de vegetação, utilizando-se vasos plásticos pretos com capacidade para $3,5 \mathrm{~kg}$, colocados sobre bancada de madeira $(5 \times 1 \mathrm{~m})$. Foram colocados em cada vaso $3 \mathrm{~kg}$ de substrato, composto de terra de subsolo, esterco de curral e casca de arroz carbonizada, na proporção $3: 1: 1+3 \mathrm{~kg}$ de superfosfato simples $/ \mathrm{m}^{3}$, sendo regados diariamente.

Para as espécies $S$. multijuga e $S$. macranthera, foram semeadas a uma profundidade de $2 \mathrm{~mm}$ a $5 \mathrm{~mm}, 10$ sementes/vaso, enquanto que para $S$. granulosoleprosum e T. micrantha foram semeadas 20 sementes/vaso.

Para acelerar e uniformizar o processo germinativo, foram empregados tratamentos para superar a dormência das sementes. As sementes de T. micrantha foram imersas em ácido sulfúrico concentrado (98\%) durante 20 minutos, seguido de lavagem em água corrente por uma hora, permanecendo em hidratação durante 24 horas. As sementes de $S$. multijuga e $S$. macranthera foram imersas em água quente $\left(100{ }^{\circ} \mathrm{C}\right)$ e deixadas em repouso até o esfriamento, por 24 horas (Davide et al., 1995). As sementes de S. granulosoleprosum passaram por pré-embebição em água destilada durante 2 horas, sendo este tratamento obtido por meio de ensaios preliminares.

Foram avaliados, além da Testemunha (sem herbicida), quatro herbicidas préemergentes, conforme apresentados na Tabela 1.

$\mathrm{Na}$ aplicação dos herbicidas foi empregado um pulverizador costal manual pressurização por $\mathrm{CO}_{2}$, a pressão de 45 psi, distribuindo $300 \mathrm{~L}$ de calda por hectare.

As características avaliadas foram: a) emergência de plântulas; b) sobrevivência; c) desenvolvimento das mudas (altura, diâmetro do colo e acúmulo de matéria seca da parte aérea) e d) efeitos fitotóxicos dos herbicidas empregados, em relação à testemunha.

A emergência de plântulas foi obtida por meio de contagens realizadas diariamente, enquanto a sobrevivência, altura, diâmetro do colo e matéria seca da parte aérea das mudas foram avaliadas no final do experimento, 120 dias após a aplicação dos herbicidas. A avaliação da altura foi realizada com auxílio de uma régua milimetrada e o diâmetro do colo com paquímetro $(0,05 \mathrm{~mm})$. Para avaliação da matéria seca da parte aérea, as plantas foram cortadas, colocadas em sacos de papel e secas em estufa com circulação de ar forçada a $70{ }^{\circ} \mathrm{C}$, durante 48 horas.

A avaliação dos efeitos fitotóxicos foi realizada por meio de descrições da sintomatologia e comparadas com as apresentadas por Vidal (1997) e Rodrigues \& Almeida (1998).

$\mathrm{O}$ experimento foi realizado em delineamento de blocos casualizados, com cinco tratamentos e quatro repetições. Cada tratamento foi representado por um vaso dentro do bloco. Os dados de emergência de plântulas e sobrevivência das mudas foram transformados em raiz quadrada de $\mathrm{Y}+1.0$ e analisados, utilizando o programa SISVAR (Ferreira, 1998). As médias dos tratamentos foram comparadas pelo teste de Scott-Knot a 5 $\%$ de probabilidade.

Com base nos resultados da emergência das plântulas e sobrevivência das mudas, foi elaborada uma matriz de equivalência para recomendação dos herbicidas, de acordo 
com o comportamento das espécies. O critério de classificação utilizado foi relacionado ao grau de interferência, considerando-se a média geral dos tratamentos. Os tratamentos com valores acima da média foram convencionados com sinal positivo $(+)$; aqueles abaixo da metade do percentual médio foram convencionados com sinal negativo (-) e aqueles com valores intermediários entre estas duas classes foram convencionados com mais ou menos $( \pm)$.

\section{RESULTADOS E DISCUSSÃO}

De acordo com a Tabela 2, pode-se observar que após cento e vinte dias da aplicação os herbicidas de pré-emergência não afetaram a emergência de plântulas de $S$. multijuga, mas afetaram a sobrevivência de mudas (Tabela 3 ).

A testemunha e o acetochlor não diferiram estatisticamente entre si e foram superiores aos demais. Os herbicidas imazapyr e atrazina promoveram menores índices de sobrevivência. Embora na emergência de plântulas não tenha havido efeito significativo entre os tratamentos (Tabela 2), a testemunha apresentou maior valor absoluto.

Os herbicidas também influenciaram as características de crescimento avaliadas (altura, diâmetro do colo e acúmulo de matéria seca). Em relação à altura e diâmetro do colo das mudas de $S$. multijuga, verificou-se que nas parcelas com aplicação de oxyfluorfen e acetochlor, as mudas apresentaram maior crescimento absoluto (Figura 1). Por outro lado, o maior acúmulo de matéria seca foi observado no tratamento com acetochlor e na testemunha.

S. macranthera apresentou diferença significativa entre os diferentes tratamentos empregados, em relação à emergência de plântulas (Tabela 2). $\mathrm{O}$ oxyfluorfen promoveu o menor índice de emergência, sendo inferior aos demais tratamentos, que não diferiram entre si. Quanto à sobrevivência das mudas (Tabela 3), o menor percentual observado foi no imazapyr, enquanto o acetochlor e atrazina não diferiram da testemunha e foram superiores ao oxyfluorfen. Em relação às características de crescimento estudadas (Figura, 1), pode-se observar que a testemunha foi superior a todos os tratamentos com herbicidas, considerando-se os valores absolutos.

S. granuloso-leprosum apresentou diferenças significativas entre os tratamentos, tanto na emergência quanto na sobrevivência das mudas, 120 dias após aplicação dos herbicidas. Na emergência de plântulas (Tabela 2) e na sobrevivência das mudas (Tabela 3), observou-se um comportamento semelhante em relação à aplicação dos herbicidas. A testemunha e o acetochlor não diferiram entre si e foram superiores aos demais tratamentos. Nos tratamentos com imazapyr e atrazina não houve sobrevivência. Em relação às características de crescimento (Figura 1), pode-se observar que a testemunha foi superior aos demais tratamentos, à exceção no tratamento com acetochlor, no qual as mudas apresentaram desempenho satisfatório, superior em termos absolutos, ao observado na testemunha.

T. micrantha foi afetada de forma significativa pela aplicação dos herbicidas. $\mathrm{Na}$ emergência de plântulas (Tabela 2), observa-se que apesar da testemunha ter sido superior em termos de valor absoluto, não diferiu estatisticamente do imazapyr, acetochlor e atrazina e foram superiores ao tratamento com aplicação de oxyfluorfen. Por outro lado, apesar da alta taxa de emergência de plântulas, os herbicidas promoveram altas taxas de mortalidade das mudas, consequentemente, a testemunha foi superior a todos os herbicidas na sobrevivência de mudas (Tabela 3).

Considerando-se as características de crescimento de $T$. micrantha apresentadas na Figura 1, observa-se que, no tratamento com aplicação de atrazina as mudas apresentaram maiores valores absolutos na altura e diâmetro do colo. No entanto, apresentaram menor acúmulo de matéria seca do que a testemunha.

De acordo com os resultados obtidos, pode-se inferir que os herbicidas empregados, se utilizados com critério, podem ser recomendados para o controle de plantas daninhas na 
implantação de florestas, através de modelos consorciando-se diferentes espécies. No entanto, de acordo com a Tabela 4, pode-se observar que o herbicida acetochlor apresentou menor interferência tanto na emergência de plântulas como na sobrevivência de mudas das espécies estudadas, em termos absolutos.

Deve-se salientar que o herbicida oxyfluorfen é o mais comumente empregado para o controle de plantas daninhas na fase de pré-emergência, em áreas de reflorestamentos (Ribeiro, 1988; Wiecheteck, 1988; Barrichelo \& Managó, 1988; Rodrigues et al., 1988; Pascoal \& Nakano, 1988 e Thomaz et al., 1988). Segundo os autores, o oxyfluorfen apresenta grande eficiência, impedindo a competição das plantas daninhas com as espécies florestais, sem interferir no seu desenvolvimento.

Os herbicidas empregados promoveram efeitos diferenciados, tanto na sobrevivência das mudas quanto nas características de crescimento (altura, diâmetro do colo e acúmulo de matéria seca). Por outro lado, deve-se considerar que, um fator crucial que pode ter interferido em tais características foi a densidade das mudas em cada tratamento, no final do experimento, 120 dias após aplicação dos herbicidas. Isto foi decorrente das diferenças nas taxas de mortalidade e sobrevivência das mudas. Como houve diferenças entre os herbicidas, este fator influenciou diretamente tais características.

Outro fator que deve ser considerado aqui é a utilização de tratamentos para superar a dormência das sementes. Como se trata de espécies pioneiras, segundo a classificação de Oliveira-Filho et al. (1995), uma característica comum a todas elas é a presença de sementes dormentes. Deste modo, os tratamentos empregados para superar a dormência de sementes, apesar de mostrarem-se eficientes, comprovado pelo tratamento testemunha, pode de alguma forma ter interferido nos resultados, uma vez que não se pode comprovar a sua total eficiência. De acordo com Bewley \& Black (1994), mesmo em se tratando de um lote de sementes, pode-se encontrar sementes com diferentes graus de dormência, que é uma característica influenciada por fatores genéticos.

Os efeitos fitotóxicos observados e descritos, para todas as espécies (Tabela 5), corroboram as descrições já mencionadas em literatura por Vidal (1997) e Rodrigues \& Almeida (1998). Todos os herbicidas empregados apresentaram, ainda, um eficiente controle sobre a infestação de plantas daninhas, cuja presença pode ser comprovada na testemunha. Dentre as espécies identificadas pode-se citar: azedinha (Oxalis latifolia), tiririca (Cyperus sp.), guanxuma (Sida sp.), erva-moura (Solanum americanum), picão preto (Bidens pilosa), brachiária (Brachiaria decumbens) e outras gramíneas. De acordo com (Rodrigues \& Almeida, 1998), os herbicidas empregados também apresentam eficiente controle de várias plantas daninhas de ocorrência natural em áreas de reflorestamento.

Dentre os herbicidas testados, o oxyfluorfen foi aplicado em pré-emergência, em plantios de eucalipto, com o objetivo de avaliar o seu efeito sobre o desenvolvimento das mudas (Ribeiro, 1988). O autor verificou que Eucalyptus camaldulensis e E. tereticornis foram altamente resistentes e não apresentaram sintomas de toxidez. E. citriodora, E. resinifolia e $E$. intermedia apresentaram queima dos tecidos apicais, mas recuperaram-se com facilidade. E. pellita e E. urophyla sofreram danos ligeiramente mais severos e $E$. pilularis e E. cloeziana sofreram danos mais graves, com algumas plantas chegando a morrer.

Em outro trabalho, com avaliação de oxyfluorfen na germinação de sementes de Araucaria angustifolia, foi verificado que as dosagens de 2,0;4,0 e 6,0L/ha não influenciaram a germinação desta, nem afetaram a altura e diâmetro do colo das mudas (Barrichelo \& Managó, 1988).

As respostas quanto à aplicação de herbicidas, nas plantas daninhas, são influenciadas também pelas características genéticas (Vidal, 1997). Do mesmo modo, as espécies florestais, à semelhança das testadas neste trabalho, podem apresentar diferentes respostas, uma vez que os indivíduos, dentro de uma população de uma área de coleta de 
sementes, podem apresentar grande variabilidade, principalmente em se tratando de espécies alógamas.

A grande variabilidade genética entre indivíduos alógamos é confirmada por Allard (1971), que menciona a presença de alta taxa de heterozigose. Segundo Ramalho et al. (2000), a variação genética é comum a todas as espécies e ocorre devido às diferenças de constituição genética, surgidas através de mutação. Neste sentido, a seleção natural existe em função da variação entre os indivíduos em cada população, sendo gerada pelos processos que criam e ampliam a variabilidade.

Considerando-se, ainda, a utilização dos herbicidas aqui empregados, deve-se entender que sua utilização, em áreas de preservação permanente, só poderia ser recomendada de acordo com as prescrições do produto e sob rigoroso controle técnico. Comprovadamente, os herbicidas podem causar sérios danos ao meio ambiente (Gelmini, 1988; Pitelli \& Karam, 1988 e DiTomaso, 2000), sendo o dano, alguma vezes, irreversível (Vidal, 1997). Tais herbicidas podem provocar, ainda, a intoxicação de aves, peixes e abelhas (Vidal, 1997). Portanto, é necessária uma avaliação mais acurada para a sua utilização em implantação de florestas, em áreas de preservação permanente.

\section{CONCLUSÕES}

a) $\mathrm{O}$ acetochlor apresentou os melhores resultados, em termos de segurança às espécies cultivadas, para ser empregado na implantação de florestas por meio de semeadura direta;

b) Na emergência de plântulas, $S$. macranthera e $T$. micrantha mostraram-se bastante susceptíveis à ação do oxyfluorfen, enquanto $S$. granuloso-leprosum mostrou-se bastante susceptível à utilização do imazapyr e atrazina e $S$. multijuga não foi afetada pelos herbicidas empregados;

c) Na sobrevivência das mudas, $S$. multijuga foi afetada pela ação do imazapyr e da atrazina; $S$. macranthera mostrou-se bastante sensível à ação de imazapyr; S. granulosoleprosum mostrou-se bastante sensível ao imazapyr, atrazina e oxyfluorfen e T. micrantha ao oxyfluorfen. Exceto T. micrantha, as demais espécies mostraram-se bastante sensíveis ao imazapyr. Deste modo, não se recomenda sua utilização para povoamentos com as referidas espécies;

d) As espécies foram afetadas diretamente pelos herbicidas empregados na altura, diâmetro do colo e acúmulo de matéria seca;

e) Os efeitos fitotóxicos não diferiram daqueles já mencionados em literatura, mas em alguns casos houve recuperação das mudas das espécies, em relação ao dano inicial promovido pelos herbicidas.

\section{REFERÊNCIAS BIBLIOGRÁFICAS}

ALLARD, R.W. Princípios do melhoramento genético de plantas. São Paulo: Edgar Blucher, 1971. 381p.

BARRICHELO, J.C.; MANAGÓ, J.D. Ensaio preliminar sobre os efeitos do oxyfluorfen na germinação de Araucaria angustifolia (Bert.) O. Ketz aplicado em pré-emergência. In: SEMINÁRIO SOBRE PLANTAS DANINHAS E O USO DE HERBICIDAS EM REFLORESTAMENTO, 1988, Rio de Janeiro. Rio de Janeiro: ABRACAVE, 1988. p.1-16. Volume irregular, várias paginações. 
BEWLEY, J.D.; BLACK, M. Seeds: physiology of development and germination. New York: Plenum Press, 1994. 445p.

BRASIL. Ministério da Agricultura e Reforma Agrária. Normais Climatológicas de 1961-1990. Brasília: Secretaria Nacional de Irrigação/Departamento Nacional de Meteorologia, 1992. 84p.

BUDOWSKI, G. Distribution of tropical American rain forest species in the light of sucessional process. Turrialba, v.15, n.1, p.40-42, 1965.

DAVIDE, A.C.; BOTELHO, S.A. Análise crítica dos programas de recomposição de matas ciliares em Minas Gerais. In: SIMPÓSIO MATA CILIAR: CIÊNCIA E TECNOLOGIA, Belo Horizonte, 1999. Anais...Lavras: UFLA/FAEPE/CEMIG, 1999. p.172-188.

DAVIDE, A.C.; FARIA,J.M.R.; BOTELHO, S.A. Propagação de espécies florestais. Belo Horizonte: CEMIG/UFLA/FAEPE, 1995. 45p.

DAVIDE, A.C.; FERREIRA, R.A.; FARIA, J.M.R.; BOTELHO, S.A. Restauração de matas ciliares. Informe Agropecuário, v.21, n.207, p.65-74, 2000.

DITOMASO, J.M. Invasive weeds in rangelands: species, impacts and management. Weed Science, Lawrence, v.48, n.2, p.255-265, 2000.

FERREIRA, D.F. Sisvar - Sistema de análise de variância para dados balanceados. Lavras: UFLA, 1998. 19p.

GELMINI, G.A. Herbicidas: indicações básicas. Campinas: Fundação Cargil, 1988. 334p.

LEI Florestal de Minas Gerais. Belo Horizonte, 1991. 34p.

PASCOAL, W.C.; NAKANO, J.A. Tecnologia e aplicação de herbicidas pré-emergentes em reflorestamento. In: SEMINÁRIO SOBRE PLANTAS DANINHAS E O USO DE HERBICIDAS EM REFLORESTAMENTO, 1988, Rio de Janeiro. Rio de Janeiro: ABRACAVE, 1988. p.1-11. Volume irregular, várias paginações.

PIÑA-RODRIGUES, F.C.M.; COSTA, L.G.S.; REIS, A. Estratégias de estabelecimento de espécies arbóreas e o manejo de florestas tropicais. In: CONGRESSO FLORESTAL BRASILEIRO, 6, Campos do Jordão. 1992. Anais... Campos do Jordão, 1992. p.676684.

PITELLI, R.A.; KARAM, D. Ecologia das plantas daninhas e sua interferência em culturas florestais. In: SEMINÁRIO SOBRE PLANTAS DANINHAS E O USO DE HERBICIDAS EM REFLORESTAMENTO, 1988, Rio de Janeiro. Rio de Janeiro: ABRACAVE, 1988. p.1-20. Volume irregular, várias paginações.

RAMALHO, M.A.P.; SANTOS, J.B.; PINTO, C.B.P. Genética na agropecuária. Lavras: UFLA, 2000. 472p.

RODRIGUES, B.N.; ALMEIDA, F.S. Guia de herbicidas: Londrina: Ed. Londrina, 4ed., 1998. 648p. 
RODRIGUES, J.J.V; COELHO, J.P.; KARAN, D.; ZANÚNCIO, I.; TAKADA, H.M. Efeitos de doses crescentes de oxyfluorfen no controle de plantas daninhas na cultura do Eucalyptus. In: SEMINÁRIO SOBRE PLANTAS DANINHAS E O USO DE HERBICIDAS EM REFLORESTAMENTO, 1988, Rio de Janeiro. Rio de Janeiro: ABRACAVE, 1988. p.1-11. Volume irregular, várias paginações.

RIBEIRO, G.T. Uso de herbicida pré-emergente em Eucalyptus spp. na região do Cerrado. In: SEMINÁRIO SOBRE PLANTAS DANINHAS E O USO DE HERBICIDAS EM REFLORESTAMENTO, 1988, Rio de Janeiro. Rio de Janeiro: ABRACAVE, 1988. p.1-12. Volume irregular, várias paginações.

SUN, D.; DICKINSON, G.R.; BRAG, A.L. Direct seeding of Alphitonia petriei (Rhamnaceae) for gully revegetation in tropical northern Australia. Forest Ecology and Management, v.73, n.1-3, p.249-257, 1995.

SWAINE, M.D.; WHITMORE, T.C. On the definition of ecological species groups in tropical rain forests. Vegetatio, v.75, p.81-86, 1988.

THOMAZ, S.K.; MAIA, S.M.; BORSSATO, I.; TERADA, M. A opção para o uso de préemergente em reflorestamento no Vale do Rio Doce. In: SEMINÁRIO SOBRE PLANTAS DANINHAS E O USO DE HERBICIDAS EM REFLORESTAMENTO, 1988, Rio de Janeiro. Rio de Janeiro: ABRACAVE, 1988. p.1-12. Volume irregular, várias paginações.

VIDAL, R.A. Herbicidas: mecanismos de ação e resistência de plantas. Porto Alegre: R.A. VIDAL, 1997. 165p.

WIECHETECK, M. Aplicação de Goal-Br no controle de plantas daninhas em Pinus. In: SEMINÁRIO SOBRE PLANTAS DANINHAS E O USO DE HERBICIDAS EM REFLORESTAMENTO, 1988, Rio de Janeiro. Rio de Janeiro: ABRACAVE, 1988. p.1-21. Volume irregular, várias paginações.

Tabela 1. Nome comum, nome comercial e doses dos herbicidas de pré-emergência utilizados no experimento. UFLA, Lavras - MG, 2002. 


\begin{tabular}{ccc}
\hline \multicolumn{2}{c}{ Nome dos Produtos } & Doses \\
\hline Comum & Comercial & p.c. L/ha \\
\hline Testemunha & Testemunha & 0,0 \\
Imazapyr & Arsenal & 3,0 \\
Atrazina & Atrazina & 5,0 \\
Acetochlor & Fist & 3,0 \\
Oxyfluorfen & Goal & 4,5 \\
\hline
\end{tabular}

TABELA 2. Efeito de herbicidas de pré-emergência na emergência de plântulas de quatro espécies arbóreas de ocorrência em matas ciliares, 120 dias após a aplicação. UFLA, Lavras - MG, 2002.

\begin{tabular}{lcccc}
\hline & \multicolumn{4}{c}{ Emergência de plântulas (\%) } \\
\cline { 2 - 5 } Tratamentos & S. multijuga & S. macranthera & S. granuloso-leprosum & T. micrantha \\
\hline Testemunha & $100,00 \mathrm{a}$ & $100,00 \mathrm{a}$ & $100,00 \mathrm{a}$ & $100,00 \mathrm{a}$ \\
Imazapyr & $67,41 \mathrm{a}$ & $86,15 \mathrm{a}$ & $02,50 \mathrm{~b}$ & $77,67 \mathrm{a}$ \\
Atrazina & $66,25 \mathrm{a}$ & $69,19 \mathrm{a}$ & $08,33 \mathrm{~b}$ & $60,75 \mathrm{a}$ \\
Acetochlor & $73,48 \mathrm{a}$ & $79,46 \mathrm{a}$ & $76,66 \mathrm{a}$ & $74,24 \mathrm{a}$ \\
Oxyfluorfen & $54,73 \mathrm{a}$ & $30,35 \mathrm{~b}$ & $46,66 \mathrm{~b}$ & $15,93 \mathrm{~b}$ \\
\hline C.V (\%) & 17,98 & 19,92 & 32,55 & 17,50 \\
\hline
\end{tabular}

Na coluna, as médias seguidas por uma mesma letra, não diferem entre si, pelo teste de Scott-Knot, a 5\% de probabilidade.

TABELA 3. Efeito de herbicidas de pré-emergência na sobrevivência de mudas de quatro espécies arbóreas de ocorrência em matas ciliares, 120 dias após a aplicação. UFLA, Lavras - MG, 2002.

\begin{tabular}{lcccc} 
& \multicolumn{4}{c}{ Sobrevivência de mudas (\%) } \\
\cline { 2 - 5 } Tratamentos & S. multijuga & S. macranthera & S. granuloso-leprosum & T. micrantha \\
\hline Testemunha & $100,00 \mathrm{a}$ & $100,00 \mathrm{a}$ & $100,00 \mathrm{a}$ & $100,00 \mathrm{a}$ \\
Imazapyr & $03,57 \mathrm{~b}$ & $05,00 \mathrm{c}$ & $00.00 \mathrm{~b}$ & $47,29 \mathrm{~b}$ \\
Atrazina & $17,14 \mathrm{~b}$ & $70,83 \mathrm{a}$ & $00.00 \mathrm{~b}$ & $15,95 \mathrm{c}$ \\
Acetochlor & $64,99 \mathrm{a}$ & $90,00 \mathrm{a}$ & $74,16 \mathrm{a}$ & $19,97 \mathrm{c}$
\end{tabular}




\begin{tabular}{lcccc} 
Oxyfluorfen & $38,21 \mathrm{~b}$ & $43,33 \mathrm{~b}$ & $08,33 \mathrm{~b}$ & $08,60 \mathrm{c}$ \\
\hline C.V $(\%)$ & 38,83 & 22,56 & 31,01 & 25,25
\end{tabular}

Na coluna, as médias seguidas por uma mesma letra, não diferem entre si, pelo teste de Scott-Knot, a 5\% de probabilidade.

TABELA 4. Matriz para recomendação dos herbicidas, na emergência de plântulas e sobrevivência de mudas das espécies estudadas. UFLA, Lavras - MG, 2002.

\begin{tabular}{lcccccc}
\hline & \multicolumn{5}{c}{ Herbicidas } \\
\hline & \multicolumn{5}{c}{ Emergência de plântulas } & Média \\
\cline { 2 - 6 } Espécie & imazapyr & atrazina & acetochlor & oxyfluorfen & $(\%)$ \\
\hline S. multijuga & \pm & \pm & + & \pm & 72,37 \\
S. macranthera & + & \pm & + & - & 73,03 \\
S. granuloso-leprosum & - & - & + & + & 46,83 \\
T. micrantha & + & \pm & + & - & 65,71
\end{tabular}

Sobrevivência de mudas

\begin{tabular}{lccccc}
\hline S. multijuga & - & - & + & \pm & 44,78 \\
S. macranthera & - & + & + & \pm & 61,83 \\
S. granuloso-leprosum & - & - & + & - & 36,49 \\
T. micrantha & + & - & \pm & - & 38,36
\end{tabular}

Legenda: (+) percentual acima da média do tratamento; (-) abaixo da metade do valor médio do tratamento e $( \pm)$ percentual intermediário entre as duas classes. 


\section{Efeito fitotóxico}

1. Senna multijuga

imazapyr - queima do ápice da raiz; plântula com cotilédones queimados e/ou murchos; plântula com queima do hipocótilo; plântula com cotilédones semi-abertos ou fechados, unidos verticalmente e/ou sem parte aérea e plântula com folíolos semi-abertos ou fechados verticalmente;

atrazina - plântula com cotilédones encarquilhados; plântula completamente queimada e/ou murcha; plântula com cotilédones com murcha e queima, começando do ápice para a base.

acetochlor - plântula com hipocótilo e cotilédones secos; plântula com áreas cloróticas em ambos os cotilédones; plântulas apresentando alguns folíolos de cor ferrugínea/clara com posterior queima.

oxyfluorfen - plântula com cotilédones atrofiados, apresentando ápices avermelhados; plântula completamente murcha; plântula com cotilédones retorcidos (encarquilhados, apresentando manchas queimadas); plântula com cotilédones apresentando clorose e murcha; plântula com protófilos cloróticos e folíolos queimados; plântula com queima no ápice dos cotilédones; plântula com parte aérea queimada;

testemunha $\quad-29$ plântulas de espécies invasoras

\section{Senna macranthera}

imazapyr - plântula com ápice radicular necrosado, queimado ou murcho; plântula com cotilédones completamente murcho e queimado ou com mancha clorótica; plântula com folíolos reduzidos; plântula com cotilédones fechados, unidos verticalmente; plântula com hipocótilo queimado; plântula com cotilédones semi-abertos; plântula pouco desenvolvida e/ou sem parte aérea;

atrazina - plântula com mancha escura num dos bordos dos cotilédones; plântula com clorose nos cotilédones; plântulas com queima dos protófilos; plântula com parte aérea atrofiada;

acetochlor - plântula com protófilos atrofiados; plântula com protófilos queimados; plântula com folíolos fechados e murchos no ápice; plântula com folíolos de cor ferrugínea/clara, queimados no ápice.

oxyfluorfen - plântula com folíolos queimados;

testemunha $\quad-10$ plântulas de espécies invasoras;
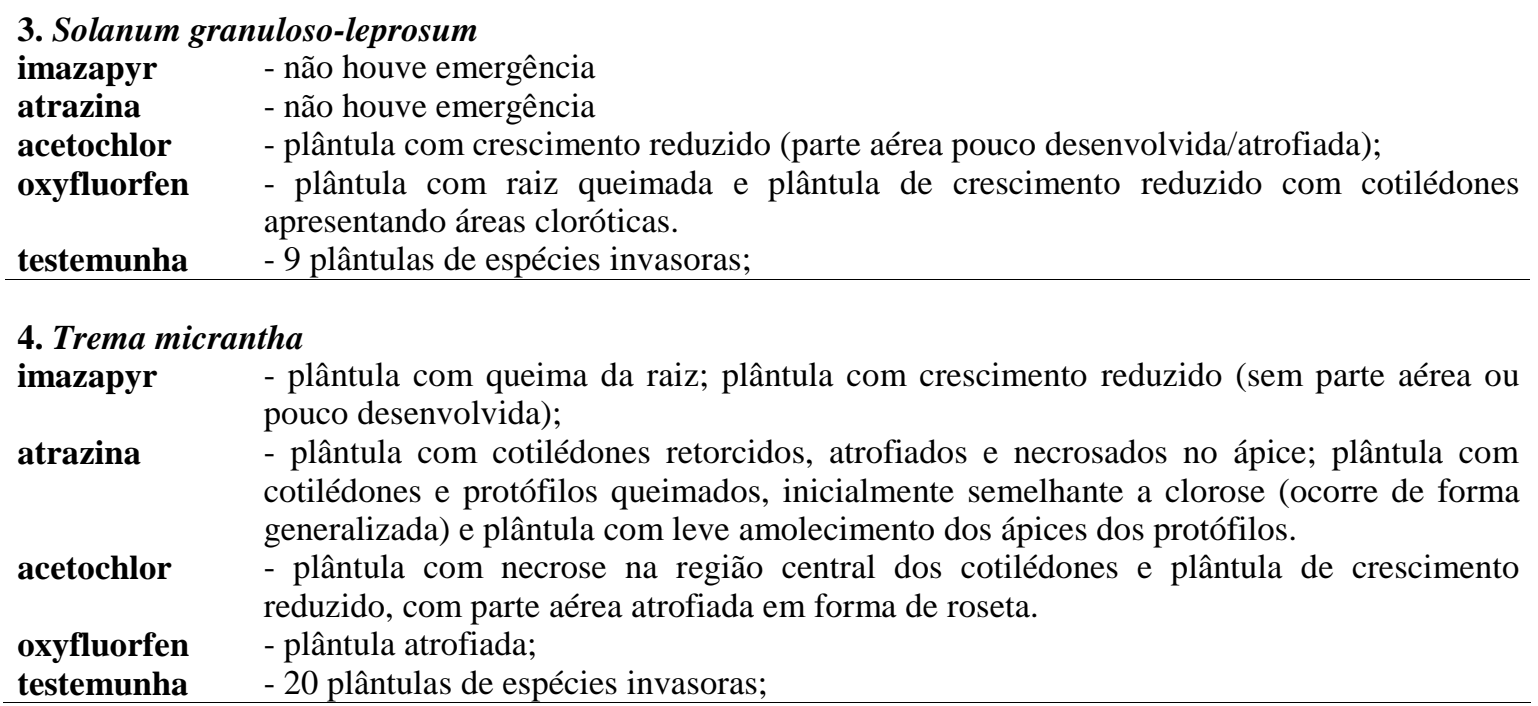

TABELA 5. Descrição dos efeitos fitotóxicos em função dos herbicidas empregados. UFLA, Lavras - MG, 2002. 

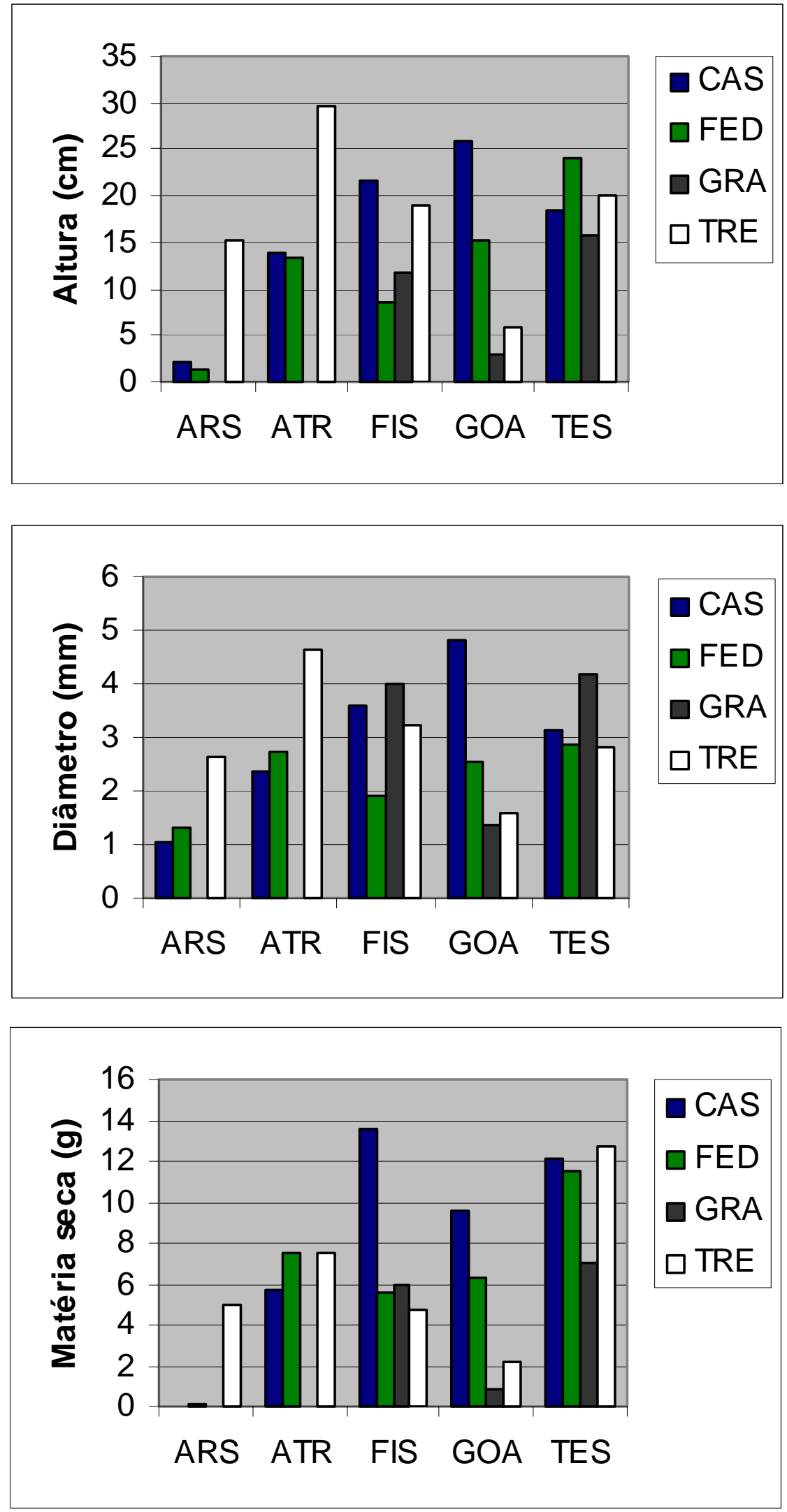

FIGURA 1. Avaliação da altura da parte aérea, diâmetro do colo e acúmulo de matéria seca da parte aérea, 120 dias após aplicação de herbicidas préemergentes, em $S$. multijuga (CAS), S. macranthera (FED), S. granuloso- 
leprosum (GRA) e T. micranhta (TRE). UFLA, Lavras - MG, 2002. (ARS imazapyr; ATR - atrazina; FIS - acetochlor; GOA - oxyfluorfen e TES testemunha). 